\title{
Effect of Various Tilted Positions of a Thin Fin on Natural Convection of Laminar Viscous Flow in a Square Cavity
}

\author{
Syed Fazuruddin ${ }^{*}$, Seelam Sreekanth ${ }^{2}$, G Sankara Sekhar Raju ${ }^{3}$ \\ ${ }^{1}$ Department of Mathematics, Sreenivasa Institute of Technology and Management Studies, Chittoor 517001, India \\ ${ }^{2}$ Department of Computer Science Engineering, Institute of Aeronautical Engineering, Dundigal, Hyderabad 5000 043 , India \\ ${ }^{3}$ Department of Mathematics, JNTUA College of Engineering, Pulivendula 516390, Andhra Pradesh, India
}

Corresponding Author Email: fazuruddinsyed@gmail.com

https://doi.org/10.18280/ijht.390527

Received: 11 August 2020

Accepted: 27 September 2021

\section{Keywords:}

convection, square cavity, thin fin, laminar

two-dimensional flow, buoyancy force

\begin{abstract}
An exhaustive numerical investigation is carried out to analyze the role of an isotherma heated thin fin on fluid flow and temperature distribution visualization in an enclosure. Natural convection within square enclosures finds remarkable pragmatic applications. In the present study, a finite difference approach is performed on two-dimensional laminar flow inside an enclosure with cold side walls and adiabatic horizontal walls. The fluid flow equations are reconstructed into vorticity - stream function formulation and these equations are employed utilizing the finite-difference strategy with incremental time steps. The parametric study includes a wide scope of Rayleigh number, Ra, and inclination angle $\theta$ of the thin fin. The effect of different Rayleigh numbers ranging $\mathrm{Ra}=10^{4}-10^{6}$ with $\mathrm{Pr}=0.71$ for all the inclination angles from $0^{\circ}-360^{\circ}$ with uniform rotational length of angle 450 of an inclined heated fin on fluid flow and heat transfer have been investigated. The heat transfer rate within the enclosure is measured by means of local and average Nusselt numbers. Regardless of inclination angles of the thin fin, a slight enhancement in the average Nusselt number is observed when Rayleigh number increased for both the cases of the horizontal and vertical position of the thin fin. When the fin has inclined no change in average Nusselt number is noticed for distinct Rayleigh numbers.
\end{abstract}

\section{INTRODUCTION}

The role of obstacles in fluid flows is an ever-green phenomenon in this modern scientific research, especially for the natural convective flows of biological fluids, obstacles create a considerable impact on fluid flows and heat transfer. So far, a countable number of research articles published to show the impact of various kinds of obstacles on fluid flows and heat transformation. Esfe et al. [1] presents SIMPLE algorithm-based simulation of free convection flow inside a square cavity with a hot circular cylindrical obstacle. Pordanjani et al. [2] studied the effect of magnetic field on the natural convection of $\mathrm{Al}_{2} \mathrm{O}_{3}$ - water nanofluid inside a square enclosure with two heated square obstacles and sinusoidal temperature distribution is considered along the side walls. Karki et al. [3] studied the effect of adiabatic mono and multiple obstacles within a square enclosure in different position filled with laminar incompressible fluid using Lattice Boltzmann Method (LBM). Mohebbi et al. [4] conducted numerical investigation of nanofluid thermogravitational convection within a $\Gamma$-shaped enclosure that consists of a local heater by the lattice Boltzmann method (LBM). Ahmed et al. [5] examined the buoyancy-driven heat transfer enhancement and fluid flow of nanofluids inside inclined enclosures containing an adiabatic obstacle (square and circular cylinder) in the presence of heat generation/absorption effect. Chakkingal et al. [6] investigate natural convection driven by a horizontal temperature gradient and a vertical concentration gradient in fluid-filled enclosures in presence of multiple obstructions inside it. Ganesh et al. [7] present the numerical study of heat generating $\gamma \mathrm{Al}_{2} \mathrm{O}_{3}-\mathrm{H}_{2} \mathrm{O}$ nanofluid inside a square cavity with multiple obstacles of different shapes (Centre's of the circular obstacles are located at $(0.25 \mathrm{~L}$, $0.25 \mathrm{H}),(0.25 \mathrm{~L}, 0.75 \mathrm{H}),(0.75 \mathrm{~L}, 0.25 \mathrm{H})$ and $(0.75 \mathrm{~L}, 0.75 \mathrm{H})$ with radius $(0.1 \mathrm{~L}))$. In this article it is focused to find the impact of uniformly rotating heated fin placed at the centre of the square cavity on natural convective fluid flow and heat transfer. Alam et al. [8] in their study numerically inspected the impact of governing parameters on magnetized thermal flow field within a cool top driven square enclosure by placing a heater at the base, the side walls of the cavity are insulated. They kept various types of obstacles at the centre of cavity and concluded that for each obstacle irrespective of shape the Average Nusselt number declines at cold wall when Ha rises. Parvin et al. [9] numerical examination shows the impact of MHD for the variation of Heat transfer on natural convective flow within a square enclosure consisting of a hot circular solid obstacle. Their investigation is done with the variation of $\mathrm{Ra}, \mathrm{Ha}$, and $\mathrm{Nu}$ in addition to the diameter of heated obstacle. They found a significant impact of Ra on fluid flow and its temperature. Chowdhury et al. [10] inspected the fluid flow and transformation of heat in view of free convection with in a triangular cavity consisting of a circular insulated obstacle and the cavity filled with immersed porous medium. They maintained heated base wall and cold inclined side walls for the enclosure. They found high impact of circular obstacle on temperature and fluid flow, rise in heat and size of the obstacle worsens the average $\mathrm{Nu}$. Chowdhury et al. [11] implemented 
finite element method for the examination of the parameters $\mathrm{Pr}, \mathrm{Nu}, \mathrm{Ha}$, Richardson number on MHD mixed convection fluid flow inside a top driven square cavity contains triangular hot body placed at the centre of the cavity. They are maintained top wall adiabatic with heated bottom wall and obstacle, among the two side walls left wall is with uniform movement. In their analysis a drastic decrement in $\mathrm{Nu}$ observed due to the obstacle as its size decreases.

Zoubair et al. [12] performed a numerical assessment of heat transfer mixed convection flow inside a vented square cavity consisting of cold circular obstacle. The SIMPLE algorithm-based investigation of three distinct outlet port locations on right side wall of enclosure, wide range investigation has been conducted for parameters like Richardson number, volume fraction of nanoparticles and found that, better heat transformation gained when the outlet port placed at the bottom of vented cavity. Keshtkar et al. [13] utilized Lattice Boltzmann technique to analyze the flow and heat transfer of a fluid inside a square cavity consists of three hot obstacles with the influence of magnetic and gravitational force. By their study they came to know that heat transmission rate in natural convection is high when compared to forced convection. In case of forced convection heat transmission, Hartmann number and ramp angle doesn't show any impact on thermal contour lines. LBM D2Q9 \& D2Q4 standard models are addressed by Naffouti et al. [14] and the obstacle impact on fluid flow and heat expansion of free convection in rectangular enclosure heated at the bottom and kept uniform cold side walls. In their investigation it is observed that the size and position of obstacle strongly influences the thermal and dynamic fields. Afolabi et al. [15] reported numerical examination of heat source impact on flow and heat transfer placed at the centre of the square cavity. They considered insulated horizontal walls and uniform cold temperature for the vertical walls of the cavity, and implemented finite element method for the parametric study. Their results exhibit rising of Ra from $10^{2}-10^{7}$ the heated fluid motion carried out to top half of enclosure and bottom half is much cooler due to buoyancy forces. Esfe et al. [16] analyzed mixed convection heat transport and fluid flow inside a lid-driven square enclosure consisting of hot rectangular obstacle. Basma Souayeh et al. [17] predicted free convection flow inside a square enclosure with partially heated obstacle positioned at the insulated bottom wall, the other walls are maintained at cold temperature. Kolsi et al. [18] investigated a free convectional entropy generation of nanofluid filled in an open enclosure consisting of an adiabatic solid block of diamond shaped. They identified that the mode of geometrical partition act as a control parameter for fluid flow and heat transmission inside the cavity.

The convective flow in a square cavity with an adiabatic circular cylinder has been addressed by Abdulkadhim et al. [19]. They maintained heated base and cooled vertical walls of the enclosure, the obstacle and top wall considered adiabatic. Khaleel et al. [20] numerically examined the impact of adiabatic obstacles on free convective fluid flow inside a 2D elliptic annulus in presence of porous medium. In their analysis the porous layer surrounded in an annulus of inner hot and outer cold elliptic cylinders the two obstacles with different lengths and position maintained throughout their study. According to their results fixing of long size obstacles in the collision of convection cells rises the heat transfer rate up to $16 \%$, and fixing of short obstacles causes heat transfer up to $19 \%$. Esfe et al. [21] examined variable properties of combined convective nanofluid flow inside a lid-driven square enclosure consisting of heated obstacle. By SIMPLE algorithm approach the impact of wide range of various parameters like Richardson number, fluid temperature, solid volume fraction, obstacle height analyzed and they presented the results in terms of isotherms and streamlines. They concluded that height of hot obstacle raises the heat transfer of the fluid. A phenomenon of Fluid flow, heat transformation \& entropy generation within a triangular cavity consisting of a revolving obstacle were studied by Akbar et al. [22]. In their investigation they considered a triangular cavity with wavy vertical hot wall, slanting cold wall and adiabatic horizontal wall and with five cases for each set of parameters with different shapes of obstacles like platelets, bricks, blades and cylinders for nanoparticles volume fraction in the range of 0.5 5 and Rayleigh number in $10^{3}-10^{6}$ range and the same behavior analyzed for entropy generation also. Emran et al. [23] investigated the isothermal obstacles impact on natural convection within a cylindrical container consisting of aspect ratio 1 that are positioned at heated base and the top of the container maintained cool. From their outcomes in the majority of the cases regular plate roughness tends to rise of Nusselt number. Emran et al. [24] observed the impact of uniform as well as non-uniform heated horizontal and vertical thin fins on free convectional micropolar fluid flow inside a square enclosure. In their observation vortex viscosity parameter decelerates velocity and heat transmission of the fluid, and effects of source non-uniform parameter on fluid flow and heat transport for high Rayleigh numbers is observed. Muthtamilselvan et al. [25] inspected the role of distinct structures of wavy circular heating obstacle on convective heat transfer contained by an enclosure packed with nanofluid. In view of their outcomes, it was noticed that the structure of wavy heating obstacle plays a crucial role in controlling of fluid flow and heat transfer.

Current numerical examination aims to investigate the fluid flow distributions inside the enclosure for the anti-clock wise rotating heated thin fin with incremental inclination angle $45^{\circ}$. The emerging fluid flow equations are evaluated using the finite difference method. The computational outcomes are depicted via streamlines, isotherms for distinct values of Rayleigh number and inclination angles of thin fin. In addition, the Nusselt numbers for the cold walls are analyzed and discussed.

\section{BASIC EQUATIONS}

Consider the 2D laminar, thermo-convection in Newtonian fluid of square enclosure with an adiabatic upper and bottom surface with internal inclined heated fin present, in an $(x, y)$ coordinate system, where $x$ is parallel to the base of the enclosure and $y$ is normal to it. The computational domain is presented in Figure 1. It is assumed that the height of the cavity is denoted by height $H$ and length is denoted by $L$. The working fluid is considered as air $\operatorname{Pr}=0.71$. The right side and left side walls of the enclosure are prescribed uniform temperatures, $T_{C}$ and $T_{C}$ respectively. The gravity acceleration $\mathrm{g}$ is taken to be in the normal direction and all the fluid properties are assumed constants except the fluid density which is considered using the Boussinesq approximation. Moreover, the Joule heating, thermal radiation, magnetic fied and viscous dissipation effects are ignored. Taking into account all the above assumptions, the governing equations 
(conservation of mass, momentum, angular momentum and energy) can be written as [26-28]:

$$
\begin{gathered}
\frac{\partial u}{\partial x}+\frac{\partial u}{\partial y}=0 \\
\rho\left(\frac{\partial u}{\partial t}+u \frac{\partial u}{\partial x}+v \frac{\partial u}{\partial y}\right)=-\frac{\partial p}{\partial x}+\mu\left(\frac{\partial^{2} u}{\partial x^{2}}+\frac{\partial^{2} u}{\partial y^{2}}\right) \\
\rho\left(\frac{\partial v}{\partial t}+u \frac{\partial v}{\partial x}+v \frac{\partial v}{\partial y}\right)=-\frac{\partial p}{\partial y} \\
+\mu\left(\frac{\partial^{2} v}{\partial x^{2}}+\frac{\partial^{2} v}{\partial y^{2}}\right)+g \beta\left(T-T_{c}\right) \\
\frac{\partial T}{\partial t}+u \frac{\partial T}{\partial x}+v \frac{\partial T}{\partial y}=\alpha\left(\frac{\partial^{2} T}{\partial x^{2}}+\frac{\partial^{2} T}{\partial y^{2}}\right)
\end{gathered}
$$

Here $\mathrm{u}, \mathrm{v}$ are the velocity variables in $\mathrm{X}$ - direction and $\mathrm{Y}$ directions respectively, $T$ is the temperature and $p$ is the pressure. The suitable fluid properties are Kinematic viscosity $v$, fluid density $\rho$, thermal diffusivity $\alpha$ and volumetric expansion $\beta$.

The initial and boundary conditions are

$$
\begin{gathered}
\text { When } t=0: u=v=0, T=0, \\
\text { for } 0 \leq x \leq L \& 0 \leq y \leq L \\
t>0: u=v=0, T=T_{c}, \\
\text { for } x=0, L \& 0 \leq y \leq L \\
u=v=0, \frac{\partial T}{\partial y}=0, \\
\text { for } y=0, L \& 0 \leq x \leq L
\end{gathered}
$$

$u=v=0, T=T_{h}$ on rotating fin.

Introducing the subsequent dimensionless variables

$$
\begin{gathered}
(x, y)=\frac{(x, y)}{L}, \quad(U, V)=\frac{(u, v)}{\alpha / L}, \tau=\frac{t}{L^{2} / \alpha}, \\
\theta=\frac{T-T_{c}}{\Delta T}, \Delta T=\frac{T_{h 1}+T_{h 2}}{2}-T_{c}, \\
\Psi=\frac{\psi}{\alpha} \text { and } \zeta=\frac{\omega}{\alpha / L^{2}}
\end{gathered}
$$

The dimensionless vorticity - stream function formulation of Eqns. (1)-(5)

$$
\begin{gathered}
\frac{\partial^{2} \Psi}{\partial X^{2}}+\frac{\partial^{2} \Psi}{\partial Y^{2}}=-\zeta \\
\left(\frac{\partial \zeta}{\partial \tau}+U \frac{\partial \zeta}{\partial X}+V \frac{\partial \zeta}{\partial Y}\right)=\operatorname{Pr}\left(\frac{\partial^{2} \zeta}{\partial X^{2}}+\frac{\partial^{2} \zeta}{\partial Y^{2}}\right)+(R a \operatorname{Pr}) \frac{\partial \theta}{\partial X} \\
\left(\frac{\partial \theta}{\partial \tau}+U \frac{\partial \theta}{\partial X}+V \frac{\partial \theta}{\partial Y}\right)=\left(\frac{\partial^{2} \theta}{\partial X^{2}}+\frac{\partial^{2} \theta}{\partial Y^{2}}\right)
\end{gathered}
$$

where,

$$
\begin{gathered}
U=\frac{\partial \Psi}{\partial Y}, \quad V=-\frac{\partial \Psi}{\partial X} \\
\zeta=-\frac{\partial U}{\partial Y}+\frac{\partial V}{\partial X}
\end{gathered}
$$

The initial and boundary conditions are

$$
\begin{gathered}
\tau=0: U=V=0, \theta=0 \\
\text { for } 0 \leq X \leq 1 \text { and } 0 \leq Y \leq 1 \\
\tau>0: U=V=0, \theta=0 \\
\text { for } X=0,1 \text { and } 0 \leq Y \leq 1 \\
U=V=0, \frac{\partial \theta}{\partial Y}=0 \text { for } Y=0,1 \text { and } 0 \leq X \leq 1
\end{gathered}
$$

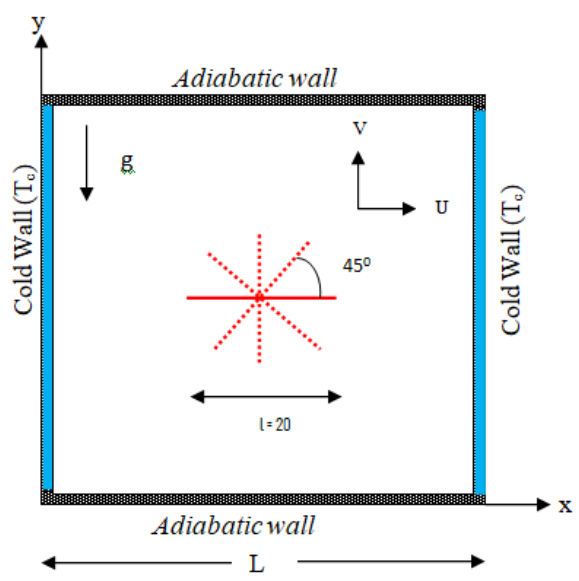

(a) Schematic diagram

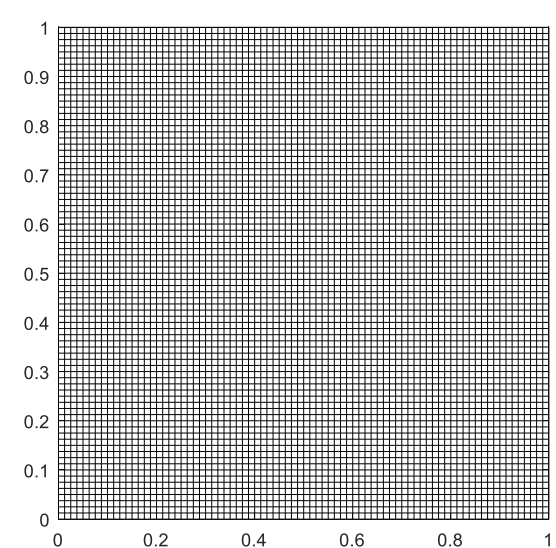

(b) Uniform mesh grid

Figure 1. Physical diagram

\section{NUMERICAL SOLUTION AND VALIDATION}

We employ a finite difference solver to solve equations governing equations with boundary conditions. This finite difference method (FDM) is stable, convergent and employs a collocation grid. The grid differencing scheme and the mesh designs for enclosure is given in Figure 1b. The velocityvorticity gradient causes strong coupling in the continuity equation and the explicit iterative method is implemented for the momentum equation. To approximate the diffusion term in 
the vorticity and energy equations, the second order central difference scheme is used. Moreover, convective terms are carried out by a second order upwind differencing scheme which gives a better solution. For the solution of the vorticity equation, the values of the vorticity at the boundaries are required. For this we employed a second order expression for $\zeta_{\mathrm{w}}$ in the form (at the bottom wall)

$$
\zeta_{w}=\frac{\Psi_{i, 2}-\Psi_{i, 1}}{2 h^{2}}
$$

by writing the stream function $\Psi$ using Taylor series expansion near the walls. Finally, the velocity components at all the grid points were calculated using the central difference approximations to $U=\frac{\partial \Psi}{\partial Y}, V=-\frac{\partial \Psi}{\partial X}$ The entire procedure was repeated in the successive time levels until $\theta$ and $\Psi$ converge at a given time level when the following convergence criteria

$$
\frac{\phi_{i, j}{ }^{n+1}-\phi_{i, j}{ }^{n}}{\phi_{i, j}{ }^{n+1}} \leq 10^{-6}
$$

for stream function and temperature have been met. In the above expression $\mathrm{n}$ represents the time level and $\phi$ represents $\theta$ and $\Psi$

The finite difference scheme is implemented for the advection terms and a $2^{\text {nd }}$ order central difference scheme is utilized for diffusion term and the second order central differencing schemes are used (see [26-34]). We adopt a uniform mesh size $80 \times 80$ in the present computations which successfully achieves mesh-independent results. Denser grids are not required as the modification in solutions is not significant beyond $80 \times 80$ dense grids. Validations with earlier studies conducted by de Vahl Davis [35], Manzari [36] and Wan et al. [28] are also included and summarized in Table 1. These validations are conducted for $P r=0.71$ (air), Excellent agreement is obtained with the $80 \times 80$ grid design. Confidence in the FDM solver is therefore justifiably high.

Table 1. Grid independence and validation for Average Nusselt number $(\mathrm{Nu})$ with $\mathrm{Pr}=0.71$

\begin{tabular}{|l|l|c|c|c|c|c|c|c}
\hline \multirow{2}{*}{$\mathbf{R a}$} & \multirow{2}{*}{$\boldsymbol{u}$} & $\begin{array}{c}\text { Ref. } \\
{[\mathbf{3 3}]}\end{array}$ & $\begin{array}{c}\text { Ref. } \\
{[\mathbf{3 7}]}\end{array}$ & $\begin{array}{c}\text { Ref. [35] } \\
\text { FEM }\end{array}$ & $\begin{array}{c}\text { Present study } \\
\mathbf{4 0 X 4 0}\end{array}$ & $\begin{array}{c}\text { Present study } \\
\mathbf{8 0 X 8 0}\end{array}$ & $\begin{array}{c}\text { Present study } \\
\mathbf{1 2 0 X 1 2 0}\end{array}$ & $\begin{array}{c}\text { Present study } \\
\mathbf{1 6 0 X 1 6 0}\end{array}$ \\
\hline $10^{4}$ & $\mathrm{Avg}$ & 2.243 & 2.084 & 2.254 & 2.2526 & 2.2455 & 2.2444 & 2.2442 \\
\hline
\end{tabular}

\section{RESULT AND DISCUSSION}

A numerical study is depicted for natural convection inside a square enclosure in presence of uniformly tilted heated fin with rotating inclination angle of $45^{\circ}$, here we considered a $360^{\circ}$ rotating heated fin of length is $20 \%$ of $\mathrm{L}$ with uniform inclination angle of $45^{\circ}$ and the rotation is based on the centre of the fin. and the heated fin is positioned at the centre of the cavity with length $20 \%$ of the side of square cavity, in this analysis numerically studied the fluid flow and heat transport in terms of streamline and isotherms for all the inclination angles $0^{\circ}, 45^{\circ}, 90^{\circ}, 135^{\circ}, 180^{\circ}, 225^{\circ}, 270^{\circ}, 315^{\circ} \& 360^{\circ}$ are graphically depicted for different Rayleigh numbers ranging $\mathrm{Ra}=10^{4}-10^{6}$ with fixed $\mathrm{Pr}=0.71$. The heat transfer rate inside the enclosure is measured by means of local and Average Nusselt number.

Figure 2 represents the streamlines for Rayleigh number $\mathrm{Ra}=10^{4}$ with $\mathrm{Pr}=0.71$ and the thin fin is rotating with an inclination angle of $45^{\circ}$ in anti clock wise direction. When the fin position is horizontal and vertical, the fluid flow is upraising and adjacent to the thin fin which is clearly observed. The viscous fluid is rise up and rises down along vertical cold walls that generate the symmetric rolls on both sides with positive and negative directions within the enclosure. When the fin is in the inclined positions $\left(45^{\circ}\right.$ and $\left.135^{\circ}\right)$, the fluid flow rise up due to buoyancy effect and falls down along the cold wall, while symmetric eddies are generated besides the heated thin fin. The corresponding temperature contours are depicted in Figure 3 for Rayleigh number $\mathrm{Ra}=10^{4}$ with the heated fin, are rotating with an inclination angle of $45^{\circ}$ in anti clock wise direction. When the isothermal hot fin is in horizontal position the temperature contours lines are blowup in the middle portion and split into two symmetric lines then proceeds towards cold walls. The distortion of the temperature lines are diminishes and moves towards colds walls. When the thin fin is at vertical position; elliptic isotherms are generated and are blowing upward because the conduction mechanism dominates the heat transfer that can be identified in these isotherms. When the heated isothermal fin is in the inclined position the corresponding isotherms are steeper near the fin inclined position and the rest of the portion the isotherms are parallel to the cold wall.
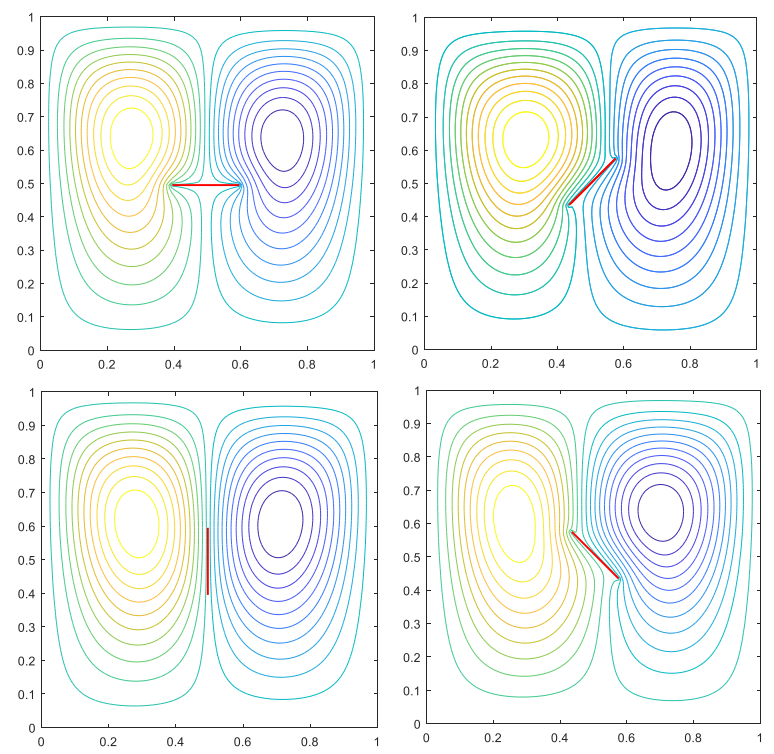

Figure 2. Streamlines for uniformly inclined fin with inclination length of angle $45^{\circ}$ for $\operatorname{Ra}=10^{4}, \mathrm{Pr}=0.71$

In Figure 4, the streamlines for Rayleigh number $\mathrm{Ra}=10^{5}$ with fixed $\mathrm{Pr}=0.71$ and as the fin is rotating with an incremental angle of $45^{\circ}$ in anti clock wise direction, the fluid is raised up from the centre of the thin fin and flow down along the cold walls which develops two symmetric convective cells above the horizontal thin fin. When the thin fin is at the vertical position, two convective cells (clock and anti-clock wise directions) are formed besides the hot fin. The size differences 
in connective cells are observed for thin fin at the inclined angle of $45^{\circ}$ and $135^{\circ}$. The convective eddies within the enclosures are occupied exclusively and the anti-clock wise rotational convective cell size is bigger than clock wise rotational convective cell for thin fin at an inclined angle of $45^{\circ}$ because the fluid flow as an effect of heat transfer acts opposite to the gravitation force. The anti-clock wise rotational convective cell size is smaller than the clock wise rotational convective cell for thin fin at an inclined angle of $135^{\circ}$. For all the rotational angles of the thin fin enlargement of smooth symmetric eddies are observed and it looks more prominent evenly shaped. The isotherms (temperature contours) at Rayleigh number $\mathrm{Ra}=10^{5}$ and the fin is rotating with an incremental angle of $45^{\circ}$ in anti clock wise direction is presented in Figure 5. The isotherms are more widen for Rayleigh number $\mathrm{Ra}=10^{5}$ when the heated fin is at horizontal as well as at vertical positions, the temperature contours are spread symmetrically at $X=0.5$. In this case the thermal boundary layers are developed uniformly along vertical cold walls. Un-uniform thermal flume is observed along the vertical wall for isothermal thin fin when it is at an inclined of $45^{\circ}$ and $135^{\circ}$. The temperature contours are equally dispatched from hot thin fin to cold vertical walls, while in all the cases of thin fin rotations the heat transfer rate is more at side walls with $\mathrm{Y}>0.5$.
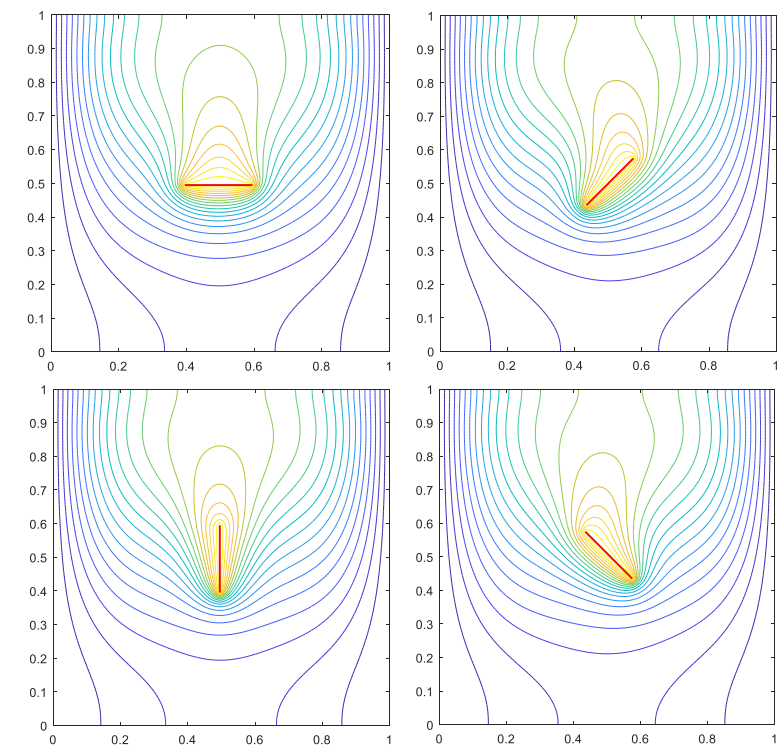

Figure 3. Isotherms for uniformly inclined fin with inclination length of angle $45^{\circ}$ for $\operatorname{Ra}=10^{4}, \operatorname{Pr}=0.710$

Figure 6 illustrates the streamlines for Rayleigh number $\mathrm{Ra}=10^{6}$ and $\mathrm{Pr}=0.71$ when the fin is rotating with an incremental inclination angle of $45^{\circ}$ in clock wise direction. The streamlines clearly show two symmetrical counter rotating cells both rising at the mid width of the cavity and falling along the vertical cold walls due to the symmetrical boundary conditions imposed at the cavity walls for the case of orientation of heated fin $0^{\circ}$ and $90^{\circ}$. For horizontal (at $0^{\circ}$ or $180^{\circ}$ ) and vertical (at $90^{\circ}$ ) positions of thin fin a similar system of two convective cells (clock and anti-clock wise directions) of same sizes are generated. The symmetric convective cells are developed above the hot fin when it is at $0^{\circ}$ or $180^{\circ}$ and also symmetric eddies are developed on both the side walls when the fin is at $90^{\circ}$ i.e., vertically located. For thin fin inclined angle at $45^{\circ}$ and $135^{\circ}$, a clear distorted symmetric eddy is obtained and the shape of eddies are significantly changed due to the dominant effect of buoyancy force acting on the fluid flows and accordingly distorted convective cells generated and a clear variation of size differences of evenly shaped convective cells are observed.
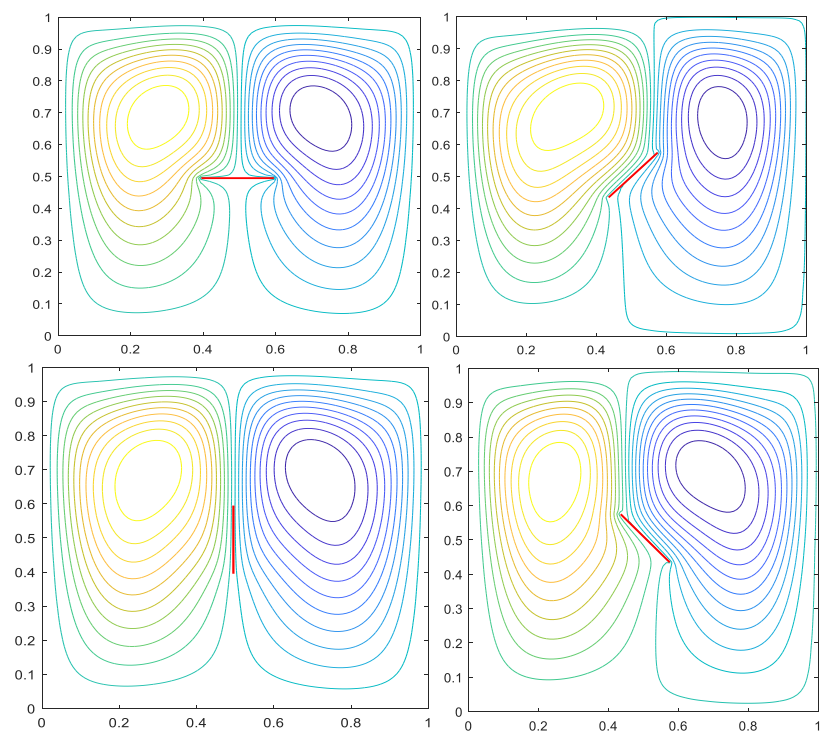

Figure 4. Streamlines for uniformly inclined fin with inclination length of angle $45^{\circ}$ for $\mathrm{Ra}=10^{5}, \mathrm{Pr}=0.71$

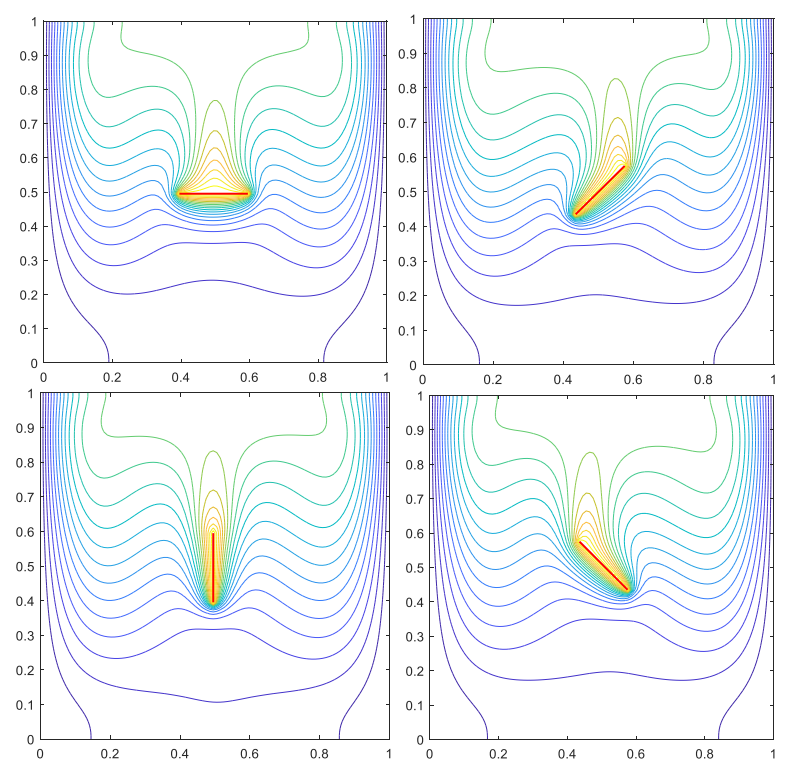

Figure 5. Isotherms for uniformly inclined fin with inclination length of angle $45^{\circ}$ for $\operatorname{Ra}=10^{5}, \operatorname{Pr}=0.71$

In Figure 7 isotherms for Rayleigh number $\mathrm{Ra}=10^{6}$ with fixed $\mathrm{Pr}=0.71$ are depicted. When the heated fin is horizontal (at $0^{\circ}$ and $180^{\circ}$ ) a wide spread of symmetric isotherms is observed and a thermal boundary layer is generated within the enclosure, a massive heat transfer rate is observed at the top corners of the cavity whereas all the thermal lines are clustered and strengthened near the cold side walls, an enlarged symmetric isotherm generated at $\mathrm{x}=0.5$ which reflects the even spread of temperature contours towards the side walls opposite to gravitation $g$. When the thin fin is vertical (at $90^{\circ}$ ) symmetric wide temperature contours generated on both the sides of the cavity and up surged towards cold walls with the same phenomenon discussed in case of horizontal fin. A non- 
symmetric thermal flume observed when the heated fin is in an inclined angle of $45^{\circ}$ and $135^{\circ}$. The heat transfer rate above the thin fin is high when compare to the heat transfer below the fin as an impact of buoyancy force. The shape of the isotherm significantly changed as Ra raised from $10^{5}$ to $10^{6}$ and is symmetric with respect to the fin, eventually the strength of the convective cell is also increased. That is the high temperature gradient near the fin consequently strengthens the convection of the fluid which is clearly observed from these isotherms.
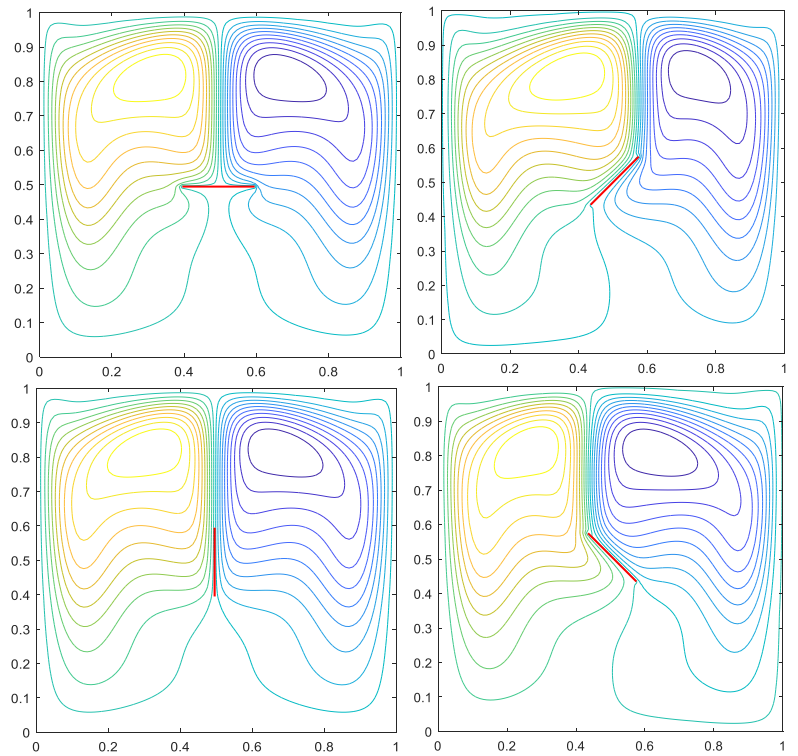

Figure 6. Streamlines for uniformly inclined fin with inclination length of angle $45^{\circ}$ for $\operatorname{Ra}=10^{6}, \operatorname{Pr}=0.71$

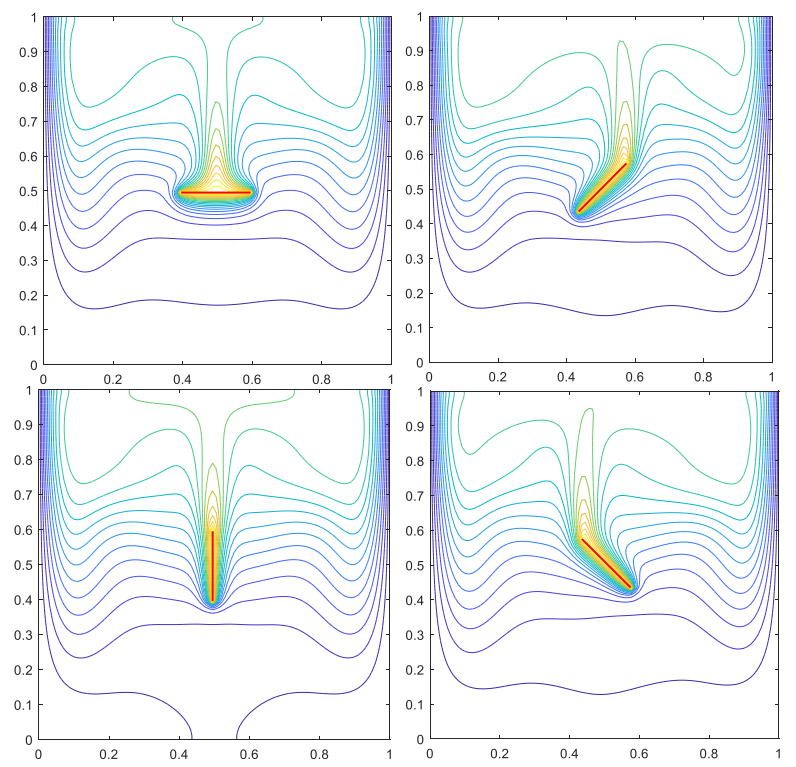

Figure 7. Isotherms for uniformly inclined fin with inclination length of angle $45^{\circ}$ for $\operatorname{Ra}=10^{6}, \operatorname{Pr}=0.71$

Figure 8 and Figure 9 present the of local Nusselt number along isothermal side walls with different inclination angles $\Theta$ of thin fin for $\mathrm{Ra}=10^{6}$ and $\operatorname{Pr}=0.71$. The symmetrical variation in local Nusselt number is observed for $\Theta=45^{\circ}$ and $135^{\circ}$, while non-symmetric distribution of the heat transfer is registered for $\Theta=0^{\circ}$ and $90^{\circ}$. The heat transfer rate is increases by enhancing the heated fin inclination angle. Low heat transfer rate at bottom portion of the side walls and massive heat transfer rate at top portion of the cold walls is observed. In particular at $\Theta=$ $90^{\circ}$ the cold walls are having greater temperature, while at $\Theta=$ $0^{0}$ the cold walls are shown opposite trend. In Figure 10 Average Nusselt number for distinct values of Rayleigh number $\left(\mathrm{Ra}=10^{4}-10^{6}\right)$ with various inclination angles $\Theta$ and $\operatorname{Pr}=0.71$ is described. This bar graph clearly visualizes the similar heat transfer is observed for $\Theta=45^{\circ}$ and $135^{\circ}$ with the respective $\mathrm{Ra}$ values and non-similar of temperature identified for $\Theta=0^{\circ}$ and $90^{\circ}$. Regardless inclination angles of thin fin the average Nusselt number is increased with rising of thermal Rayleigh number Ra.

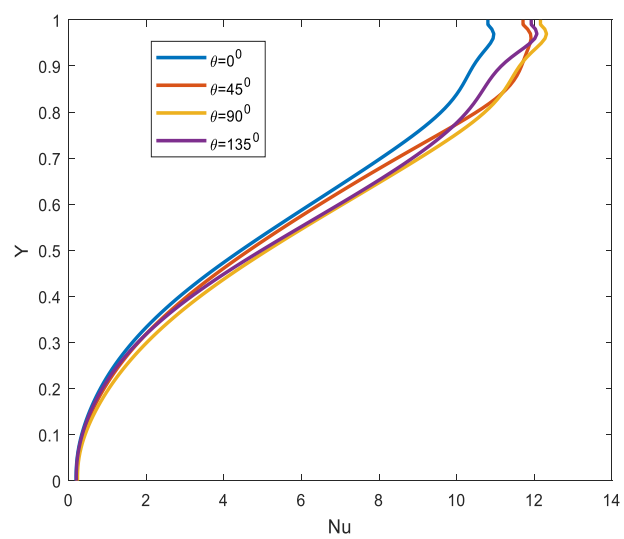

Figure 8. Local Nusselt number (along left wall) for different inclination angles $\Theta$ at $\operatorname{Ra}=10^{6}$ and $\operatorname{Pr}=0.71$

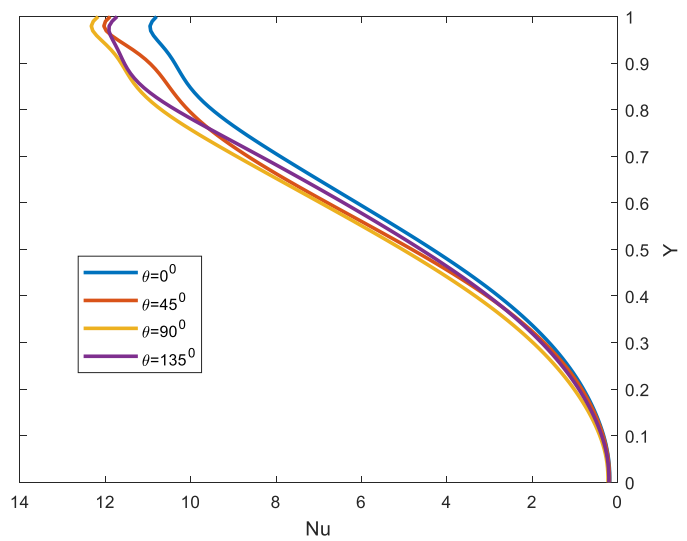

Figure 9. Local Nusselt number (along right wall) for different inclination angles $\Theta$ at $\operatorname{Ra}=10^{6}$ and $\operatorname{Pr}=0.71$

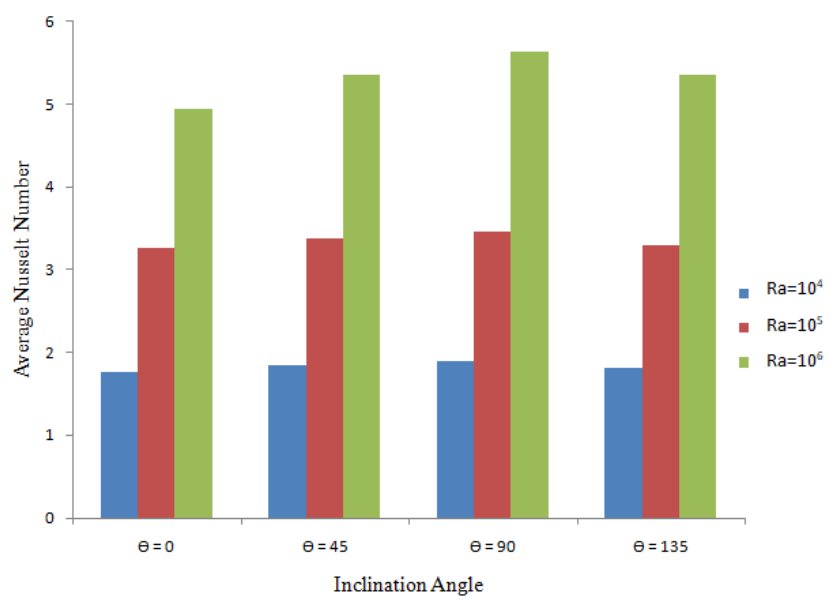

Figure 10. Average Nusselt number for different inclination angles $\Theta$ at $\operatorname{Ra}=10^{4}-10^{6}$ and $\operatorname{Pr}=0.71$ 


\section{CONCLUSIONS}

In this present paper, vorticity -stream function finite difference approach is implemented to computationally solve the problem of free convection in a square cavity consisting of heated rotational fin. The numerical phenomenon of free convectional flow and heat transfer of fluid inside a square cavity consisting of uniformly heated rotating fin situated at the centre of enclosure is analyzed. The effect of different Rayleigh numbers ranging $\mathrm{Ra}=10^{4}-10^{6}$ with $\mathrm{Pr}=0.71$ for all the inclination angles $0^{\circ}, 45^{\circ}, 90^{\circ}, 135^{\circ}, 180^{\circ}, 225^{\circ}, 270^{\circ}, 315^{\circ}$ $\& 360^{\circ}$ of rotational heated fin on fluid flow and heat transfer have been investigated. The heat transfer rate within the enclosure is measured by means of local and Average Nusselt number

- Velocity of fluid noticed symmetric and uniform for $\mathrm{Ra}=10^{4}-10^{5}$ and distorted symmetric flow is observed at $\mathrm{Ra}=10^{6}$ for all the inclination angles $0^{\circ}, 90^{\circ}, 180^{\circ}$, and $270^{\circ}$ of rotational heated thin fin.

- In general, the fluid motion rate, heat characteristics expanded by increasing the inclination angle of thin fin square enclosure.

- The uniform heat transfer rate is observed for both horizontal and vertical fin with the increase of Rayleigh numbers ranging from $10^{4}-10^{6}$ and other cases non-uniform temperature is observed for isothermal cold side walls.

- The thin-fin inclination angle as well as rotation had significant impact on the average Nusselt number of the cold wall of the enclosure including the heated fin.

- Regardless of inclination angles of thin fin, a slight enhancement in the average Nusselt number is observed when Rayleigh number increased for both the cases of horizontal and vertical position of thin fin.

- As the fin is inclined, there is no significant change noticed in average Nusselt number when Rayleigh number is enhanced.

Therefore, in the applications designing, controlling of heat transfer is possible between the enclosure and its surrounding boundary with a suitable selection of both thin fin inclination angle and Rayleigh number.

\section{REFERENCES}

[1] Esfe, M.H., Arani, A.A.A., Karimipour, A., Esforjani, S.S.M. (2014). Numerical simulation of natural convection around an obstacle placed in an enclosure filled with different types of nanofluids. Heat Transfer Research, 45(3): 279-292. https://doi.org/10.1615/HeatTransRes.2013007026

[2] Pordanjani, A.H., Jahanbakhshi, A., Ahmadi Nadooshan, A., Afrand, M. (2018). Effect of two isothermal obstacles on the natural convection of nanofluid in the presence of magnetic field inside an enclosure with sinusoidal wall temperature distribution. International Journal of Heat and Mass Transfer, 121: 565-578. https://doi.org/10.1016/j.ijheatmasstransfer.2018.01.019

[3] Karki, P., Yadav, A.K., Perumal, D.A. (2018). Study of adiabatic obstacles on natural convection in a square cavity using Lattice Boltzmann method. Journal of Thermal Science and Engineering Applications. J. Thermal Sci. Eng. Appl., 11(3): 034502. https://doi.org/10.1115/1.4041875

[4] Mohebbi, R., Izadi, M., Sajjadi, H., Delouei, A.A., Shermet, M.A. (2019). Examining of nanofluid natural convection heat transfer in a $\Gamma$-shaped enclosure including a rectangular hot obstacle using the lattice Boltzmann method. Physica A: Statistical Mechanics and Its Applications, 120831. https://doi.org/10.1016/j.physa.2019.04.067

[5] Ahmed, S.E., Elshehabey, H.M. (2018). Buoyancydriven flow of nanofluids in an inclined enclosure containing an adiabatic obstacle with heat generation/absorption: Effects of periodic thermal conditions. International Journal of Heat and Mass Transfer, 124: 58-73. https://doi.org/10.1016/j.ijheatmasstransfer.2018.03.044

[6] Chakkingal, M., Voigt, R., Kleijn, C.R., Kenjereš, S. (2020). Effect of double-diffusive convection with cross gradients on heat and mass transfer in a cubical enclosure with adiabatic cylindrical obstacles. International Journal of Heat and Fluid Flow, 83: 108574. https://doi.org/10.1016/j.ijheatfluidflow.2020.108574

[7] Ganesh, N.V., Javed, S., Al-Mdallal, Q.M., Kalaivanan, R., Chamkha, A.J. (2020). Numerical study of heat generating $\gamma \mathrm{Al}_{2} \mathrm{O}_{3}-\mathrm{H}_{2} \mathrm{O}$ nanofluid inside a square cavity with multiple obstacles of different shapes. Heliyon, 6(12): https://doi.org/10.1016/j.heliyon.2020.e05752

e05752.

[8] Alam, M.F., Bora, M., Sharma, B., Barman, R.N. (2019). Numerical investigation of magneto-hydrodynamics mixed convection in a square cavity for various shaped conducting obstacles placed at the center numerical investigation of magneto-hydrodynamics mixed convection in a square cavity for various shaped conducting obstacles placed at the center. Mathematical Modelling of Engineering Problems, 6(4): 550-556. https://doi.org/10.18280/mmep.060410

[9] Parvin, S., Nasrin, R. (2011). Analysis of the flow and heat transfer characteristics for MHD free convection in an enclosure with a heated obstacle. Nonlinear Analysis: Modelling and Control, 16(1): 89-99. https://doi.org/10.15388/NA.16.1.14117

[10] Chowdhury, R., Khan, M.A.H., Siddiki, M.N.A.A. (2015). Natural convection in porous triangular enclosure with a circular obstacle in presence of heat generation. American Journal of Applied Mathematics, 3(2): 51-58. http://dx.doi.org/10.11648/j.ajam.20150302.14

[11] Chowdhury, K., Alim, M.A. (2015). Analysis of MHD mixed convection flow within a square enclosure containing a triangular obstacle. American Journal of Applied Mathematics, 3(6): 288-296.

[12] Boulahia, Z., Wakif, A., Sehaqui, R. (2018). Heat transfer and cu-water nanofluid flow in a ventilated cavity having central cooling cylinder and heated from the below considering three different outlet port locations. Frontiers in heat and mass transfer (FHMT), 11. http://dx.doi.org/10.5098/hmt.11.11

[13] Keshtkar, M.M., Ghazanfari, M. (2017). Numerical investigation of fluid flow and heat transfer inside a 2D enclosure with three hot obstacles on the ramp under the influence of a magnetic field. Engineering, Technology \& Applied Science Research, 7(3): 1647-1657. https://doi.org/10.48084/etasr.1115

[14] Naffouti, T., Thamri, L., Naffouti, A., Zinoubi, J. (2018). 
Optimization of convective heat transfer from two heating generators into horizontal enclosure including a discrete obstacle: A lattice boltzmann comprehensive investigation. Journal of Applied Fluid Mechanics, 11(5): 1277-1286. https://doi.org/10.29252/jafm.11.05.28614

[15] Afolabi, S.I., Ojo, A.O., Oluleye, M.A., Ojo, A.A. (2019). Convective heat transfer in a square cavity with a heatgenerating body of different aspect ratios. International Journal of Engineering Research \& Technology (IJERT), 8(6): 555-562. http://dx.doi.org/10.17577/IJERTV8IS060409

[16] Esfe, M.H., Akbari, M., Karimipour, A. (2015). Mixed convection in a lid-driven cavity with an inside hot obstacle filled by an $\mathrm{Al}_{2} \mathrm{O}_{3}$-water nanofluid. Journal of Applied Mechanics and Technical Physics, 56(3): 443 453. https://doi.org/10.1134/S0021894415030141

[17] Souayeh, B., Cheikh, N. B., Beya, B.B., Lili, T. (2015). Prediction of unsteady natural convection within a square cavity containing an obstacle at high Rayleigh number value. International Letters of Chemistry, Physics and Astronomy, 55:

19-26. https://doi.org/10.18052/www.scipress.com/ILCPA.55. 19

[18] Kolsi, L., Mahian, O., Öztop, H.F., Aich, W., Borjini, M.N., Abu-Hamdeh, N., Aissia, H.B. (2016). 3D buoyancy-induced flow and entropy generation of nanofluid-filled open cavities having adiabatic diamond shaped obstacles. Entropy, 18(6): 232 https://doi.org/10.3390/e18060232

[19] Abdulkadhima, A., Al-Farhanyb, K., Abeda, A.M. (2018). Effect of adiabatic circular cylinder on the natural convection heat transfer characterizes in a porous enclosure. Chemical Engineering, 71: 1309-1314. https://doi.org/10.3303/CET1871219

[20] Khaleel, F.A., Dawood, A.S. (2014). The effect of adiabatic obstacles on natural convection inside a horizontal elliptical porous annulus. Mechanical Engineering Research, 4(1): 1 https://doi.org/10.5539/mer.v4n1p1

[21] Esfe, M.H., Ghadi, A., Esforjania, S.M., Akbari, M. (2013). Combined convection in a lid-driven cavity with an inside obstacle subjected to $\mathrm{Al}_{2} \mathrm{O}_{3}$-water nanofluid: Effect of solid volume fraction and nanofluid variable properties. Acta Physica Polonica, A., 124(4): 665-672. https://doi.org/10.12693/APhysPolA.124.665

[22] Arani, A.A.A., Kazemi, M. (2019). Analysis of fluid flow and heat transfer of nanofluid inside triangular enclosure equipped with rotational obstacle. Journal of Mechanical Science and Technology, 33(10): 4917-4929. https://doi.org/10.1007/s12206-018-0428-x

[23] Emran, M.S., Shishkina, O. (2020). Natural convection in cylindrical containers with isothermal ring-shaped obstacles. J. Fluid Mech., 882(A3): 1-26. https://doi.org/10.1017/jfm.2019.797

[24] Emran, M.S., Shishkina, O. (2020). Natural convection in cylindrical containers with isothermal ring-shaped obstacles. Journal of Fluid Mechanics, 882. https://doi.org/10.1017/jfm.2019.797

[25] Muthtamilselvan, M., Periyadurai, K., Doh, D.H. (2017). Effect of uniform and nonuniform heat source on natural convection flow of micropolar fluid. International Journal of Heat and Mass Transfer, 115: 19-34. https://doi.org/10.1016/j.ijheatmasstransfer.2017.06.134

[26] Abdelmalek, Z., Tayebi, T., Dogonchi, A.S., Chamkha,
A.J., Ganji, D.D., Tlili, I. (2020). Role of various configurations of a wavy circular heater on convective heat transfer within an enclosure filled with nanofluid. International Communications in Heat and Mass Transfer, 113:

104525 .

https://doi.org/10.1016/j.icheatmasstransfer.2020.10452 5

[27] Venkatadri, K., Bég, O.A., Rajarajeswari, P., Prasad, V.R. (2020). Numerical simulation of thermal radiation influence on natural convection in a trapezoidal enclosure: Heat flow visualization through energy flux vectors. International Journal of Mechanical Sciences, 171: 105391. https://doi.org/10.1016/j.ijmecsci.2019.105391

[28] Wan, C., Patnaik, B.S.V., Wei, G.W. (2001). A new benchmark quality solution for the buoyancy-driven cavity by discrete singular convolution. Numerical Heat Transfer: Part B: Fundamentals, 40(3): 199-228. https://doi.org/10.1080/104077901752379620

[29] Venkatadri, K., Gaffar, S.A., Prasad, V.R., Khan, B.M.H., Beg, O.A. (2019). Simulation of natural convection heat transfer in a 2-D trapezoidal enclosure. International Journal of Automotive and Mechanical Engineering, 16(4): $7375-7390$ https://doi.org/10.15282/ijame.16.4.2019.13.0547

[30] Venkatadri, K., Abdul Gaffar, S., Suryanarayana Reddy, M., Ramachandra Prasad, V., Khan, B.M., Anwar Beg, O. (2020). Melting heat transfer analysis on magnetohydrodynamics buoyancy convection in an enclosure: a numerical study. Journal of Applied and Computational Mechanics, 6(1): 52-62. https://dx.doi.org/10.22055/jacm.2019.28761.1504

[31] Venkatadri, K., Maheswari, S., Lakshmi, C.V., Prasad, V.R. (2018). Numerical simulation of lid-driven cavity flow of micropolar fluid. In IOP Conference Series: Materials Science and Engineering, 402(1): 012168.

[32] Venkatadri, K. (2017). Hydromagneto quadratic natural convection on a lid driven square cavity with isothermal and non-isothermal bottom wall. Engineering Computations, $34(8)$ : 2463-2478. https://doi.org/10.1108/EC-06-2017-0204

[33] Venkatadri, K., GouseMohiddin, S., Suryanarayana, R.M. (2017). Mathematical modelling of unsteady MHD double diffusive natural convection flow in a square cavity. Frontiers in Heat and Mass Transfer (FHMT), 9: 33. http://dx.doi.org/10.5098/hmt.9.33

[34] Venkatadri, K., Bég, O.A., Rajarajeswari, P., Prasad, V.R., Subbarao, A., Khan, B.M.H. (2020). Numerical simulation and energy flux vector visualization of radiative-convection heat transfer in a porous triangular enclosure. Journal of Porous Media, 23(12): 1187-1199. https://doi.org/10.1615/JPorMedia.2020033653

[35] Vahl Davis, G.D. (1983). Natural convection of air in a square cavity: A benchmark solution. International Journal Numer. Meth. Fluids, 3(3): 249-264. https://doi.org/10.1002/fld.1650030305

[36] Manzari, M.T. (1999). An explicit finite element algorithm for convection heat transfer problems. International Journal of Numerical Methods for Heat \& Fluid Flow, 9: 860-877. https://doi.org/10.1108/09615539910297932

[37] Devi, T.S., Lakshmi, C.V., Venkatadri, K., Prasad, V.R., Bég, O.A., Reddy, M.S. (2020). Simulation of unsteady natural convection flow of a Casson viscoplastic fluid in 
a square enclosure utilizing a MAC algorithm. Heat Transfer, 49(4):

https://doi.org/10.1002/htj.21690

\section{NOMENCLATURE}

Gravitational Acceleration $\left(\mathrm{m} / \mathrm{s}^{2}\right)$

Local heat transfer coefficient $\left(\mathrm{W} / \mathrm{m}^{2} \mathrm{~K}\right)$

Thermal conductivity $(\mathrm{W} / \mathrm{mK})$

Length of the cavity (m)

Length of the fin (heat source) (m)

Pressure $\left(\mathrm{N} / \mathrm{m}^{2}\right)$

Dimensionless pressure $\left(\mathrm{N} / \mathrm{m}^{2}\right)$

Nusselt number $(\mathrm{Nu}=\mathrm{hH} / \mathrm{k})$

Prandtl number $(v / \alpha)$

Rayleigh number $\left(g \beta \mathrm{L}^{3} \Delta \mathrm{T} / \mathrm{v} \alpha\right)$

Time (s)

Temperature (K)

$\begin{array}{ll}\mathrm{X}, \mathrm{y} & \text { dimensional coordinates } \\ \mathrm{X}, \mathrm{Y} & \text { Non-dimensional coordinates }\end{array}$

$\mathrm{u}, \mathrm{v} \quad$ Dimensional velocity components in $\mathrm{X}$ and $\mathrm{Y}$ direction respectively $(\mathrm{m} / \mathrm{s})$
$\mathrm{U}, \mathrm{V}$ Non-Dimensional velocity components in $\mathrm{X}$ and $\mathrm{Y}$ direction respectively $(\mathrm{m} / \mathrm{s})$

\section{Greek symbols}

$\alpha \quad$ Thermal diffusivity $\left(\mathrm{m} / \mathrm{s}^{2}\right)$

$\beta \quad$ Thermal expansion coefficient of the fluid $\left(\mathrm{K}^{-1}\right)$

$v \quad$ Kinematic viscosity $\left(\mathrm{m}^{2} / \mathrm{s}\right)$

$\mu \quad$ Dynamic viscosity $(\mathrm{kg} / \mathrm{ms})$

$\theta \quad$ Dimensionless temperature

$\rho \quad$ Fluid density of the particles $\left(\mathrm{kg} / \mathrm{m}^{3}\right)$

$\tau \quad$ dimensionless time

$\psi \quad$ dimensional stream function $\left(\mathrm{m}^{2} / \mathrm{s}^{1}\right)$

$\Psi \quad$ Non-dimensional stream function

$\omega \quad$ Dimensional vorticity $\left(\mathrm{s}^{-1}\right)$

$\zeta \quad$ Non-Dimensional vorticity

\section{Subscripts}

avg average

c cold wall

h hot wall 